\title{
Review: antiemetic drugs reduce nausea in early pregnancy
}

\author{
Jewell D, Young G. Interventions for nausea and vomiting in early pregnancy. Cochrane Database Syst Rev \\ 2002;(1):CD000145 (latest version 15 Jan 2001).

\section{QUESTION: How effective are different treatments for nausea and vomiting in early pregnancy?}

\section{Data sources}

Studies were identified by using the search strategy of the Cochrane Pregnancy and Childbirth Review Group, which includes searches of Medline and the Cochrane Controlled Trials Register and handsearches of 38 journals.*

\section{Study selection}

Studies were selected if they were randomised controlled trials of any treatments to reduce nausea and vomiting in pregnancy (NVP) at up to 20 weeks of gestation.

\section{Data extraction}

2 reviewers independently assessed studies for quality of allocation concealment and extracted data on study methods, participant characteristics, interventions, and nausea and vomiting outcomes.

\section{Main results}

23 trials were included. Antiemetic medication reduced nausea more than did placebo (12 RCTs) but caused more drowsiness and sleepiness (4 RCTs) (table). 3 trials compared Bendectin with placebo and showed a reduction in nausea similar to that with all antiemetics combined (odds ratio [OR] $0.28,95 \%$ CI 0.16 to 0.51 ). 2 trials showed no effect of vitamin B-6 on vomiting (OR 0.91 , CI 0.60 to 1.38). Pericardium 6 (p6) acupressure reduced morning sickness more than did placebo or dummy acupressure (2 RCTs) (OR 0.35 , CI 0.23 to 0.54 ), although 1 trial that could not be combined in the metaanalysis because of randomisation concerns showed no benefit. 5 trials examined hyperemesis gravidarum, and none of the interventions (adrenocorticotrophic hormone, diazepam, methylprednisolone, and ondansetron) showed a reduction in vomiting. These interventions did not show benefit for reducing hospital admissions; however, methylprednisolone or diazepam reduced the rate of readmission, and diazepam reduced the length of hospital stay.

\section{Conclusions}

Antiemetic drugs are the most effective interventions for reducing nausea and vomiting in early pregnancy. Insufficient evidence exists to support the effectiveness of pericardium 6 acupressure. None of the treatments for hyperemesis gravidarum that have been tested shows any benefit.
*An update is forthcoming with additional evidence about acupuncture, acupressure, and ginger.

Source of funding: no external funding.

For correspondence: Dr D Jewell, University of Bristol, Bristol, UK. david.jewell@ bristol.ac.uk.

Antiemetics v placebo to reduce nausea in pregnancy at up to 20 weeks of gestation $\dagger$

\begin{tabular}{|c|c|c|c|c|}
\hline Outcomes & $\begin{array}{l}\text { Number of } \\
\text { trials }\end{array}$ & $\begin{array}{l}\text { Weighted event } \\
\text { rates }\end{array}$ & RRR (95\% CI) & NNT (Cl) \\
\hline Nausea & 12 & $55 \%$ v $24 \%$ & $66 \%$ (43 to 79 ) & 4 (3 to 6$)$ \\
\hline & & & RRI (CI) & NNH (CI) \\
\hline $\begin{array}{c}\text { Drowsiness or } \\
\text { sleepiness }\end{array}$ & 4 & $14.6 \%$ V $7.3 \%$ & $98 \%$ (6 to 271$)$ & 14 (8 to 91 ) \\
\hline
\end{tabular}

tAbbreviations defined in glossary; RRR, RRI, NNT, NNH, and Cl calculated from data in article. Random effects were used for nausea; fixed effects were used for drowsiness or sleepiness.

\section{COMMENTARY}

Hippocrates believed that the womb was connected to the digestive tract and thence to the mouth and nose. He probably believed this because "the first complaint attending pregnancy is the nausea and vomiting, which begins soon after conception, and frequently continues 'till the end of the fourth month." The problem, recognised for 4 millennia or more, afflicts 50-90\% of pregnant women, but its cause and metabolic purpose, if any, remain unknown.

Although nausea and vomiting are normal pregnancy symptoms and signs in most situations, they are obnoxious and potentially disabling. The search for effective remedies has been confounded by the need to treat during embryogenesis, unknown causation, social and psychological influence of the condition, substantial placebo effect, and the spectre of legal action. ${ }^{23}$

The review by Jewell and Young summarises an unfortunately heterogeneous assortment of 23 trials "of variable quality" of interventions for NVP. Most drugs reduced NVP better than did placebo; however, the evidence favouring acupressure and ginger was weak, and no intervention was better than placebo for hyperemesis.

Bendectin was withdrawn by its manufacturer because of exhaustive defence costs against liability suits for fetal defects (all defences were successful). Yet its ingredients, doxylamine and vitamin B-6, are among the few medications classified as "risk factor A" drugs (ie, controlled studies in women fail to show risk to the fetus in the first trimester, no evidence exists for risk in later trimesters, and the possibility of fetal harm remains remote). ${ }^{4}$ Because no credible evidence of human or animal teratogenesis or other undesirable effects existed, a Canadian company began to make a generic form of doxylamine-pyridoxine (Diclectin) in 1984. Thus, the pharmacological equivalent of Bendectin has been available, to the benefit of pregnant women at least in Canada, since shortly after the original formulation was withdrawn.

Philip F Hall, MD University of Manitoba Winnipeg, Manitoba, Canada

1 Smellie W. Of nausea and vomiting. In: Smellie W. A treatise on the theory and practice of midwifery. London: New Sydenham Society, 1878:141-3.

2 Korcok M. The Bendectin debate. Can Med Assoc J 1980;123:922-8.

Leeder JS, Spielberg SP, MacLeod SM. Bendectin: the wrong way to regulate drug availability. Can Med Assoc J 1983;129:1085-7.

4 Briggs GG, Freeman RK, Yaffe SJ. Drugs in pregnancy and lactation. 6th edition. Philadelphia: Lippincott, Williams \& Wilkins, 2002. 